\title{
CBL knockdown protects cardiomyocytes against hypoxia-reoxygenation injury by downregulating GRB2 expression
}

\author{
ZHENGBING LV ${ }^{1}$, XIAOJIA LUO ${ }^{1}$, BIYING HONG ${ }^{1}$, QIRAN YE ${ }^{2}$, JIANXIONG LIU ${ }^{1}$ and YONGMEI HU ${ }^{1}$ \\ ${ }^{1}$ Department of Cardiology, The Second People's Hospital of Chengdu, Chengdu, Sichuan 610017; \\ ${ }^{2}$ Department of Biotechnology, College of Life Science Sichuan University, Chengdu, Sichuan 610000, P.R. China
}

Received June 23, 2021; Accepted September 27, 2021

DOI: $10.3892 /$ etm.2022.11111

\begin{abstract}
Myocardial ischemia-reperfusion injury (MIRI) is an event that follows a myocardial infarction. As such, close observation and appropriate patient management is paramount in the treatment process of interventional surgery. The pathogenesis of MIRI has not been fully elucidated. Therefore, the aim of the present study was to explore of novel targets for MIRI treatment whilst also determining their possible underlying mechanism of action. The plasma samples used in the present study were collected from 30 patients with ischemic cardiomyopathy and 30 healthy volunteers. H9c2 rat cardiomyoblasts were subjected to hypoxia and reoxygenation $(\mathrm{H} / \mathrm{R})$ modeling to establish an in vitro MIRI model. Initially, the expression levels of $\mathrm{Cbl}$ proto-oncogene (CBL) in ICM heart tissue, normal heart tissue, H/R-induced H9c2 cells and normal H9c2 cells were detected using quantitative PCR and western blotting. With the application of Cell Counting Kit-8, western blotting and Tunnel assay, the proliferation, oxidative stress and apoptosis of H/R-induced cells were assessed. Moreover, co-IP assay was employed to testify the interaction between CBL and GRB2. The present study revealed that CBL expression was upregulated in patients with ischemic cardiomyopathy and $\mathrm{H} / \mathrm{R}$-induced $\mathrm{H} 9 \mathrm{c} 2$ cells in comparison with that in normal heart tissue and normal H9c2 cells, respectively. The genetic silence of CBL using small interfering RNA promoted the proliferation and oxidative stress of $\mathrm{H} / \mathrm{R}$-induced cells but repressed the apoptosis. The full-length wild-type of growth factor receptor-bound protein 2 (GRB2) was ligated into pcDNA3.1 to achieve GRB2 overexpression, which revealed that GRB2 overexpression reversed the effects
\end{abstract}

Correspondence to: Dr Xiaojia Luo, Department of Cardiology, The Second People's Hospital of Chengdu, 10 Qingyun South Street, Chengdu, Sichuan 610017, P.R. China

E-mail: xiaojia1109@yeah.net

Key words: Cbl proto-oncogene, myocardial ischemia-reperfusion injury, hypoxia-reoxygenation injury, H9c2 cells, growth factor receptor-bound protein 2 of CBL knockdown on cells, suggesting that it may mediate these processes downstream. In conclusion, under hypoxic conditions, CBL knockdown promoted the proliferation and antioxidant capacity of cardiomyocytes whilst inhibiting apoptosis, by downregulating GRB2 expression. These findings revealed the underlying mechanism of action of this pathway, which can be exploited for the prevention or treatment of MIRI.

\section{Introduction}

Cardiovascular and cerebrovascular diseases are the predominant causes of human death (1). According to the current epidemiological data, it has been revealed that the number of CVD mortalities steadily increased from 12.1 million in 1990 to 18.6 million in 2019 globally (2). Ischemic cardiomyopathy (ICM) is one such type of cardiovascular disease (3). The main cause of myocardial ischemia is coronary artery stenosis, resulting in insufficient blood supply to the myocardium, which hinders aerobic metabolism in myocardial cells and reduces contractile capacity $(4,5)$. Therefore, energy supply during heart activity is rendered insufficient, which can cause arrhythmia and angina pectoris (6). In severe cases, it can result in myocardial infarction (7). For myocardial ischemia, the most effective treatment strategy is currently to quickly restore blood supply to the ischemic section of the heart. However, resuming blood flow after myocardial ischemia for a period of time may lead to myocardial contractile dysfunction and structural damage at the ischemic site, which will aggravate myocardial injury (8). This phenomenon is known as myocardial ischemia-reperfusion injury (MIRI) (8). MIRI is a condition that requires close medical attention and implementation of management following treatment, which mainly consists of coronary artery bypass or cardiopulmonary bypass surgery $(9,10)$. In addition, alleviating MIRI has been hypothesized to be the main cause for successful treatment and prolonged survival in patients (11). Coupled with the continued advancements in surgical techniques, antiplatelet and antithrombotic agents, reperfusion therapy in a timely manner can effectively preserve the patency of coronary arteries $(10,12,13)$. However, the treatment for MIRI has not been effectively improved, evidenced by $\sim 8.8$ million mortalities in 2015 
worldwide, accounting for $15.5 \%$ of all deaths that year (14). Therefore, studying the growth state and metabolic activity of cardiomyocytes is expected to yield significant results for the prevention and treatment strategies for complications caused by MIRI.

Previous studies have shown that the pathogenesis during myocardial ischemia is associated with oxidative stress, chronic inflammation and cardiomyocyte apoptosis (15-17). Reperfusion in the ischemic myocardium results in the production of oxygen free radicals (OFR), which can mediate myocardial damage (18). In addition, production of vast quantities of reactive oxygen species (ROS) during the early stages of reperfusion can lead to dysfunction of the antioxidant system in myocardial cells, causing widespread cell damage and eventually necrosis and apoptosis (19). Therefore, improving the antioxidant capacity of cells may reduce myocardial cell damage caused by MIRI. Cbl proto-oncogene (CBL) is widely expressed in various tissues and contains an $\mathrm{N}$-terminal tyrosine-kinase-binding domain, which can interact with a variety of proteins (20). Elsewhere, Cbl proteins are implicated in the regulation of multiple signal transduction (21). For instance, $\mathrm{Cdc} 42$ sequesters $\mathrm{Cbl}$ from the epidermal growth-factor receptor (EGFR) through $\beta$ PIX, thus inhibiting EGFR downregulation (22). In addition, c-Cbl, an adaptor protein, has been reported to participate in the activation of MAP kinases (23). Previous studies have revealed that CBL inhibition can alleviate cardiomyopathy injury. Using c-Cbl as an example, the silencing of c-Cbl helps to improve cardiac function in response to myocardial ischemia (24). Furthermore, CBL-knockout mice exhibit improved abilities to recover heart function following ischemia and reperfusion (24), suggesting that CBL may exert negative regulatory effects on the survival of myocardial cells in addition to angiogenesis following MIRI.

At present, the pathogenesis of MIRI has not been fully elucidated (25). Therefore, it remains in demand to actively explore novel targets and their underlying mechanism of action in MIRI. In the present study, an in vitro MIRI model was constructed through hypoxia-reoxygenation $(\mathrm{H} / \mathrm{R})$, where the target of CBL was predicted using bioinformatics analysis. The aim of the present study was to explore the effect of CBL on $\mathrm{H} / \mathrm{R}$-induced cardiomyocyte injury and to determine the underlying mechanism.

\section{Materials and methods}

Clinical samples. All procedures were performed in accordance with the Declaration of the Institutional Research Committee's Ethical standards and the 1964 Declaration of Helsinki with its later amendments. The Ethics Committee of the Second People's Hospital of Chengdu approved the involvement of human participants and the study ran from August 2017 to August 2019 (approval no. 2017081302). All patients or their parents/guardians provided written informed consent for participation after they were fully informed of the study details.

The plasma samples of 30 patients with ICM (age, $70.2 \pm 9.24$ years old; $21: 9$ males and females) and 30 healthy subjects who went to the hospital for health checkups (age, $69 \pm 8.12$ years old; 21:9 males to females) admitted to The Second People's Hospital of Chengdu (Chengdu, China) between August 2017 and August 2019 were obtained. A total of $5 \mathrm{ml}$ fasting venous blood of the study subjects was drawn into tubes containing vitamin $\mathrm{K}$ antagonists and centrifuged at $1,200 \mathrm{x}$ g for $10 \mathrm{~min}$ at $4^{\circ} \mathrm{C}$, before the supernatant was collected and stored at $-20^{\circ} \mathrm{C}$. According to World Health Organization, ICM presents as a dilated cardiomyopathy with impaired contractile performance (26). The diagnosis of ICM group and all patients in the present study were based on this. MIRI inclusion criteria: Left ventricular ejection fraction still $<40 \%$ after percutaneous coronary intervention surgery was judged as occurrence of myocardial ischemia-reperfusion injury. MIRI exclusion criteria: Patients have chest pain caused by menopausal syndrome, neurosis, gastroesophageal reflux disease, combined autoimmune diseases, malignant tumors and previous history of cardiovascular and cerebrovascular diseases (27).

Cell culture and treatment. The $\mathrm{H} 9 \mathrm{c} 2$ rat cardiomyoblasts were purchased from The Cell Bank of Type Culture Collection of the Chinese Academy of Sciences and cultured in DMEM supplemented with 15\% FBS (both Gibco; Thermo Fisher Scientific, Inc.) and $1 \%$ penicillin/streptomycin at $37^{\circ} \mathrm{C}$ in a humidified incubator with $5 \% \mathrm{CO}_{2}$.

To established a cellular MIRI model, serum/glucose-free DMEM was employed. $\mathrm{H} 9 \mathrm{c} 2$ cells $\left(1.5 \times 10^{5}\right.$ cells/well $)$ were placed in an incubator containing 94\% $\mathrm{N}_{2}, 5 \% \mathrm{CO}_{2}$ and $1 \% \mathrm{O}_{2}$ at $37^{\circ} \mathrm{C}$ to simulate hypoxia for $24 \mathrm{~h}$. Subsequently, the cells were placed in an incubator with $5 \% \mathrm{CO}_{2}$ at $37^{\circ} \mathrm{C}$ and cultured for another 24 and $48 \mathrm{~h}$ for reoxygenation at $37^{\circ} \mathrm{C}$. $\mathrm{H} 9 \mathrm{c} 2$ cells cultured with $5 \% \mathrm{CO}_{2}$ for the full $48 \mathrm{~h}$ period were used as the control group. In addition, the group that underwent $H / R$ treatment after $24 \mathrm{~h}$ transfection was designated the as H/R + small interfering RNA (si)/or Overexpression (Ov)-group.

Cell transfection. $\mathrm{H} 9 \mathrm{c} 2$ cells were seeded into six-well plates at a density of $2 \times 10^{5}$ cells/well and transfected with $1 \mu \mathrm{g}$ pcDNA3.1-growth factor receptor-bound protein 2 (GRB2; accession no. NM_030846.2) overexpression vector or pcDNA3.1 empty vector (Hunan Fenghui Biotechnology Co., Ltd.) and/or $50 \mathrm{nM}$ siRNAs against CBL (si-CBL) or negative control (si-NC; Shanghai Genepharma Co., Ltd.) using Lipofectamine ${ }^{\circledR} 2000$ (Invitrogen; Thermo Fisher Scientific, Inc.) according to the manufacturer's protocol. Following transfection for $24 \mathrm{~h}$, the cells were used for subsequent experiments. si-CBL-1 target, 5'-GGAAGCCATCGCCAA ATATGA-3'; si-CBL-2 target, 5'-GTGCTGGAAGCTCAT GGACAA-3'; si-NC target, 5'-GGCAGACAATGCGAAACA CTT-3'.

Cell Counting Kit 8 (CCK-8) assay. H9c2 cells $\left(1.5 \times 10^{4} \mathrm{cells} /\right.$ well $)$ were cultured in 96 -well plates before $10 \mu \mathrm{l}$ CCK-8 reagent (Beyotime Institute of Biotechnology) was added into each well 24 or $48 \mathrm{~h}$ after plating the cells. Cells were then incubated at $37^{\circ} \mathrm{C}$ for a further $2 \mathrm{~h}$. The absorbance in each well was measured at a wavelength of $450 \mathrm{~nm}$ using a microplate reader (Molecular Devices, LLC).

Reverse transcription-quantitative PCR (RT-qPCR). Total RNA was extracted from cells using TRIzol $^{\circledR}$ reagent (Invitrogen; Thermo Fisher Scientific, Inc.) and then reverse 
Table I. Primer sequences used for reverse transcription-quantitative PCR.

\begin{tabular}{lll}
\hline Gene & \multicolumn{1}{c}{ Sequence (5'-3') } & Product sizes (bp) \\
\hline CBL (Rat) & F: GCTTCTCTTTGGCTTGTGCG \\
& R: CTGGTGAAGCGAGGAATGGA \\
Growth factor receptor bound protein 2 (Rat) & F: TGCCTAGAGCCACTAAGGGT \\
& R: GGAGAGAAACGGTGGACAGG \\
Proliferating cell nuclear antigen (Rat) & F: AGTTTTCTGCGAGTGGGGAG \\
Ki67 (Rat) & R: AAGACCTCAGAACACGCTGG \\
& F: TTCCAGACACCAGACCATGC \\
GAPDH (Rat) & R: GGTTCTAACTGGTCTTCCTGGTT \\
CBL (Homo sapiens) & F: TCTCTGCTCCTCCCTGTTCT \\
RAPDH (Homo sapiens) & F: TACGGCCAAATCCGTTCACA \\
& R: GTGGCTGAAGATGAGGGACA \\
& F: GACTCATGACCACAGTCCATGC \\
\hline
\end{tabular}

CBL, Cbl proto-oncogene; F, forward; R, reverse.

transcribed into cDNA using Universal RT-PCR kit (cat. no. QN0943; Beijing Baiao Laibo Technology Co., Ltd.) according to the manufacturer's protocols. The mRNA expression levels were measured using SYBR Green Master Mix (cat. no. MT0017; Beijing Baiao Laibo Technology Co., Ltd.) on a StepOnePlus $^{\mathrm{TM}}$ Real-time PCR system (Applied Biosystems; Thermo Fisher Scientific, Inc.). The thermocycling conditions were as follows: Initial denaturation at $95^{\circ} \mathrm{C}$ for $3 \mathrm{~min}$; followed by 40 cycles of denaturation at $95^{\circ} \mathrm{C}$ for $30 \mathrm{sec}$, annealing at $60^{\circ} \mathrm{C}$ for $30 \mathrm{sec}$ and extension at $72^{\circ} \mathrm{C}$ for $30 \mathrm{sec}$. The primer sequences used are listed in Table I. GAPDH was used as internal reference and the relative mRNA expression levels were calculated using the $2^{-\Delta \Delta \mathrm{Cq}}$ method (28).

Western blot analysis. Total proteins were extracted from each group of H9c2 cells using RIPA lysis buffer (Beyotime Institute of Biotechnology) and then quantified with bicinchoninic acid protein assay kit (cat. no. P0012S; Beyotime Institute of Biotechnology). Equal amount of proteins ( $20 \mu \mathrm{g}$ per lane) were separated by $10 \%$ SDS-PAGE and then transferred onto PVDF membranes. Following blocking with 5\% non-fat milk for $2 \mathrm{~h}$ at room temperature, the membranes were incubated with primary antibodies against CBL (cat. no. ab228785; 1:1,000; Abcam), GRB2 (cat. no. ab32111; 1:1,000; Abcam), Ki67 (cat. no. ab16667; 1:1,000; Abcam), proliferating cell nuclear antigen (PCNA; cat. no. ab18197; 1:1,000; Abcam), Bcl-2 (cat. no. ab32124; 1:1,000; Abcam), Bax (cat. no. ab32503; 1:1,000; Abcam), caspase-3 (cat. no. ab32351; 1:5,000; Abcam) cleaved caspase-3 (cat. no. ab2302; 1:500; Abcam) or GAPDH (cat. no. ab8245; $1: 1,000 ;$ Abcam) at $4^{\circ} \mathrm{C}$ overnight. The membranes were then incubated with HRP-conjugated goat anti-rabbit secondary antibodies (cat. no. ab97080; 1:5,000; Abcam) for $2 \mathrm{~h}$ at room temperature. Enhanced chemiluminescence reagent (Thermo Fisher Scientific, Inc.) was used to visualize the protein bands and the gray values were assessed using ImageJ (version 1.8; National Institutes of Health).
Detection of oxidation stress. H9c2 cells were collected and lysed using a cell lysis buffer (cat. no. P0013; Beyotime Institute of Biotechnology), followed by centrifugation at $10,000 \mathrm{x} \mathrm{g}$ for $10 \mathrm{~min}$ at $4^{\circ} \mathrm{C}$. In total, $200 \mu \mathrm{l}$ supernatant was collected. Lactate dehydrogenase (LDH; cat. no. A020-2-2), superoxide dismutase (SOD; cat. no. A001-3-2) and malondialdehyde (MDA; cat. no. A003-4-1) detection kits were used according to the manufacturers' protocols (Nanjing Jiancheng Bioengineering Institute). The activity values were calculated based on absorbance using a microplate reader (Thermo Fisher Scientific, Inc.).

TUNEL assay. $\mathrm{H} 9 \mathrm{c} 2$ cells $\left(2 \times 10^{4}\right.$ cells/well) were seeded into a 24-well plate and assay was stained using a TUNEL kit (cat. no. C1086; Beyotime Institute of Biotechnology) according to the manufacturer's protocols. Briefly, cells were first stained by $4 \%$ paraformaldehyde for $30 \mathrm{~min}$ at room temperature followed by incubation with PBS containing $0.3 \%$ Triton X-100 for $5 \mathrm{~min}$ at room temperature. TUNEL working fluid was added and cells were incubated for another $1 \mathrm{~h}$ at $37^{\circ} \mathrm{C}$ away from the light. Subsequently, Antifade Mounting Medium with DAPI (cat. no. P0131; Beyotime Institute of Biotechnology) was employed to treat the cells. A total of 10 randomly selected visual fields were observed using a fluorescence microscope (magnification, x200; Olympus Corporation). Apoptosis rate was calculated as follows: Apoptosis rate $\%=$ number of positive apoptotic cells/total number of cells x $100 \%$.

Co-immunoprecipitation (co-IP) assay. H9c2 cells were collected and lysed in pre-cooled cell lysis buffer (cat. no. P0013; Beyotime Institute of Biotechnology) containing protease inhibitors at $0^{\circ} \mathrm{C}$. The supernatant was collected after centrifugation at $13,000 \mathrm{x}$ g for $10 \mathrm{~min}$ at $4^{\circ} \mathrm{C}$. Subsequently, $0.2 \mathrm{mg}$ protein A agarose beads (cat. no. 20366; Thermo Fisher Scientific, Inc.) that were washed with $100 \mu \mathrm{l}$ PBS buffer were added to $500 \mu \mathrm{g}$ lysis buffer and incubated with $2 \mu \mathrm{g} \mathrm{IgG}$ 

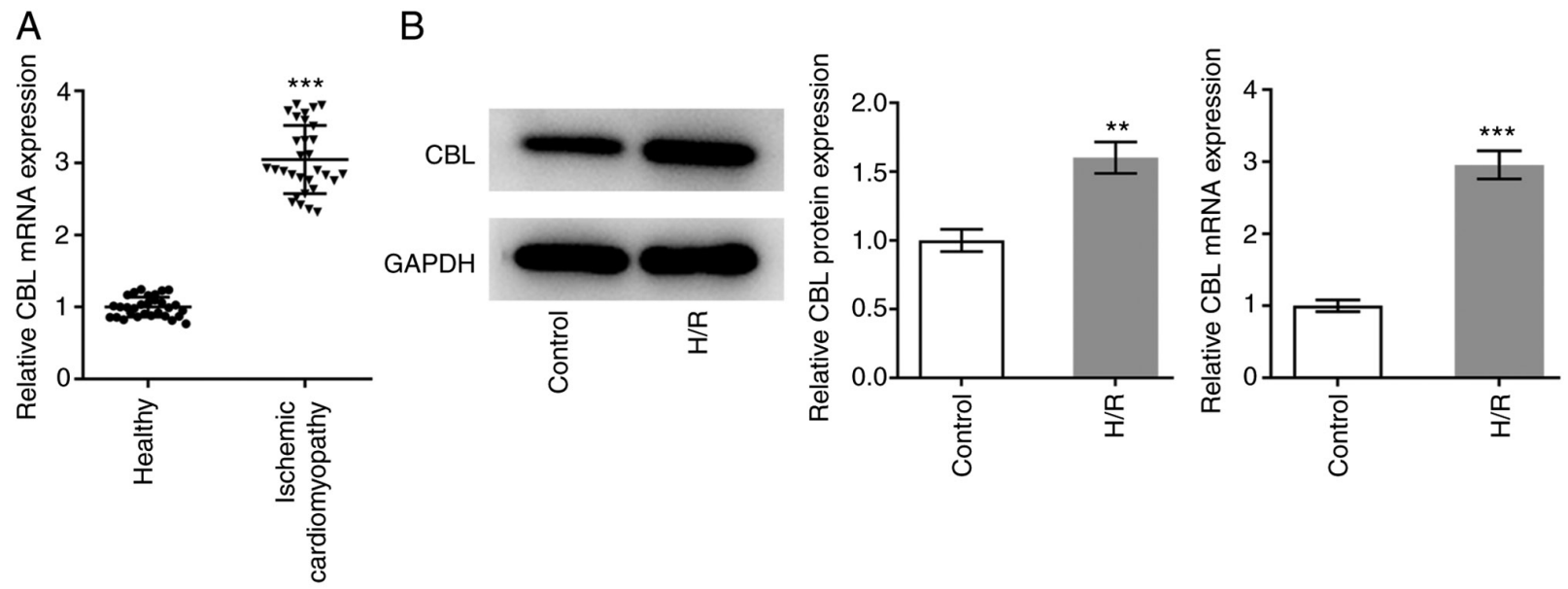

Figure 1. Analysis of CBL expression. (A) Expression levels of CBL in blood samples of patients with ischemic cardiomyopathy and the healthy subjects were measured using RT-qPCR. ${ }^{* * *} \mathrm{P}<0.001$ vs. Healthy. (B) Expression levels of CBL in H/R-induced H9c2 cells and normally cultured H9c2 cells were measured using RT-qPCR and western blot analysis. ${ }^{* *} \mathrm{P}<0.01$ and ${ }^{* * * *} \mathrm{P}<0.001$ vs. Control. CBL, Cbl proto-oncogene; RT-qPCR, reverse transcription-quantitative PCR; $\mathrm{H} / \mathrm{R}$, hypoxia-reoxygenation.

antibody (1:1,000; cat. no. ab172730; Abcam) or CBL antibody (cat. no. 2747; 1:50; Cell Signaling Technology, Inc.) overnight at $4^{\circ} \mathrm{C}$ with slow shaking. Following the IP reaction and centrifugation at $1,000 \mathrm{x} \mathrm{g}$ at $4^{\circ} \mathrm{C}$ for $2 \mathrm{~min}$, the agarose beads were washed with lysis buffer and boiled for $5 \mathrm{~min}$ at $100^{\circ} \mathrm{C}$ by adding $15 \mu 12 \mathrm{X}$ SDS sample buffer. This sample were then subjected to western blotting.

Bioinformatics analysis. Search Tool for the Retrieval of Interacting Genes/Proteins (STRING, version 11.0; https://string-db.org/) (29) is an online database used for searching known protein interactions. CBL and GRB2 were first entered together at the multiple-proteins interface and the species Homo sapiens was selected before the result was automatically displayed.

Statistical analysis. Data are presented as the mean \pm standard deviation and statistical analysis was performed using GraphPad Prism version 8.0 (GraphPad Software, Inc.). Comparisons among multiple groups were performed using a one-way ANOVA followed by a Tukey's post hoc test and unpaired Student's t test between two groups. All cellular experiments were performed $\geq$ three times from three different cultures. $\mathrm{P}<0.05$ was considered to indicate a statistically significant difference.

\section{Results}

Analysis of CBL expression. The expression levels of CBL in patients with ICM and healthy individuals were measured using RT-qPCR. There were 30 individuals in each group and the expression levels were statistically analyzed. The expression levels of CBL in the plasma of patients with ICM were significantly higher compared with those in the healthy individuals (Fig. 1A). Subsequently, expression levels of CBL in H/R-induced H9c2 cells and normally cultured H9c2 cells were measured using RT-qPCR and western blot analysis. The expression levels in $\mathrm{H} / \mathrm{R}$-induced cells were significantly higher compared with those in cells cultured normally (Fig. 1B).
CBL knockdown promotes the proliferation and oxidative stress resistance of $H / R$-induced $H 9 c 2$ rat cardiomyoblasts. To explore the specific role of CBL in H/R-induced cells, CBL expression was knocked down by transfection with specific siRNAs before the efficacy of knockdown was assessed using RT-qPCR and western blot analysis. The expression levels of CBL were significantly lower in cells transfected with si-CBL-1 compared with those in cells transfected with si-NC (Fig. 2A). si-CBL-1 was chosen for subsequent experiments due to the higher potency compared with si-CBL-2 (Fig. 2A). The H9c2 cells were subsequently divided into the following four groups: Control group, $H / R$ group, $\mathrm{H} / \mathrm{R}+$ si-NC group and the $\mathrm{H} / \mathrm{R}+\mathrm{si}-\mathrm{CBL}$ group. Viability in each group of cells was first detected using CCK-8 assay. After 24 and $48 \mathrm{~h}$ of treatment the results showed that cell viability in the H/R group was significantly lower at both time points compared with that in the control group. In addition, viability in the $\mathrm{H} / \mathrm{R}+$ si-CBL group was significantly higher compared with that in the $\mathrm{H} / \mathrm{R}+$ si-NC group, indicating that CBL knockdown alleviated the damage caused by H/R (Fig. 2B). Similarly, PCNA and Ki67 protein expression levels in the cells of each group were detected using western blot analysis and RT-qPCR. Compared with the control group, the expression levels of PCNA and Ki67 were significantly downregulated in $\mathrm{H} 9 \mathrm{c} 2$ cells after $\mathrm{H} / \mathrm{R}$ induction. In addition, their expression levels in the H/R + si-CBL group were significantly higher compared with that in the $\mathrm{H} / \mathrm{R}+$ si-NC group, suggesting that CBL knockdown also promoted H/R-induced cell proliferation (Fig. 2C). Subsequently, the antioxidant capacity of each group of cells was assessed by specifically measuring LDH, SOD and MDA. From the calculated results, SOD levels were found to be significantly decreased in the $\mathrm{H} / \mathrm{R}$ group compared with those in the control, but were significantly upregulated in the $\mathrm{H} / \mathrm{R}+\mathrm{si}-\mathrm{CBL}$ group compared with those in the H/R + si-NC group (Fig. 2D). By contrast, LDH and MDA levels exhibited an opposite trend (Fig. 2D). This suggests that CBL knockdown improved the antioxidant capacity of H/R-induced cells. 

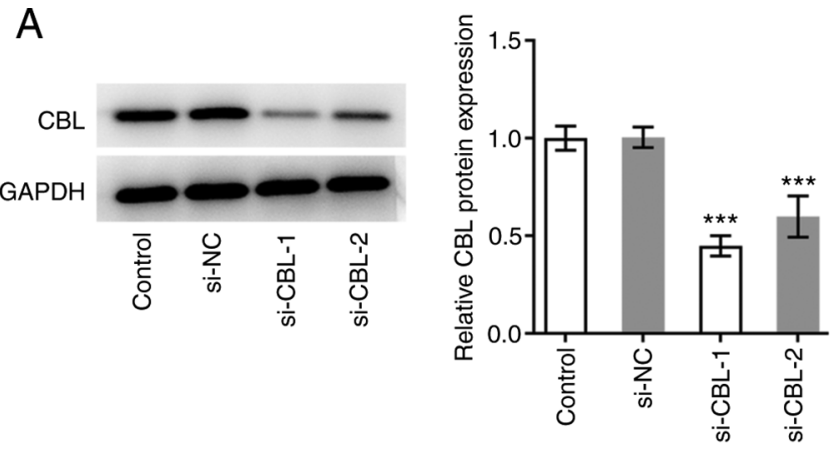
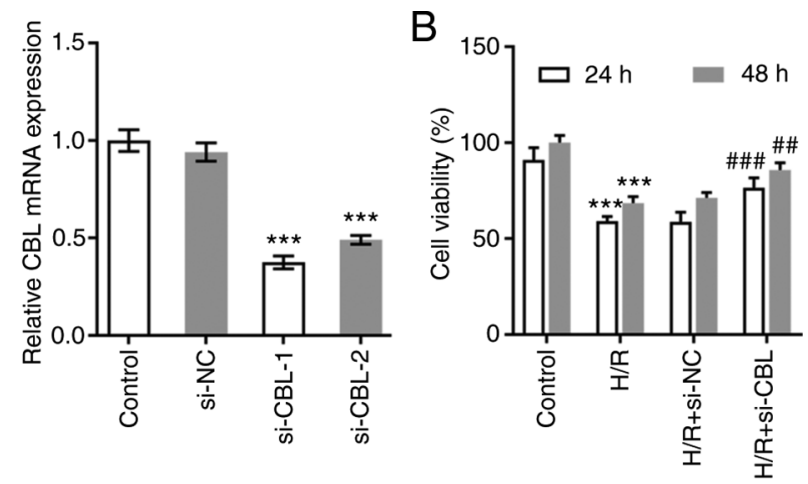

C

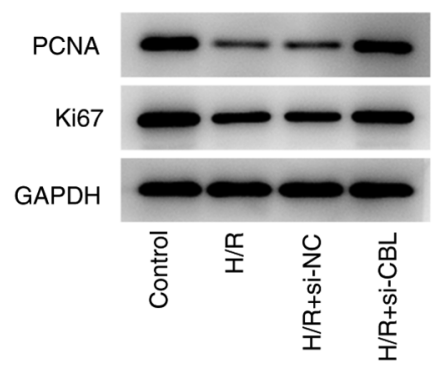

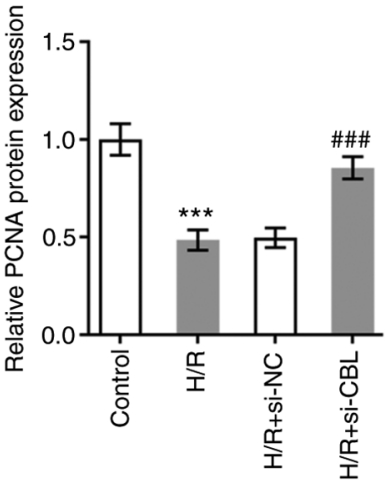

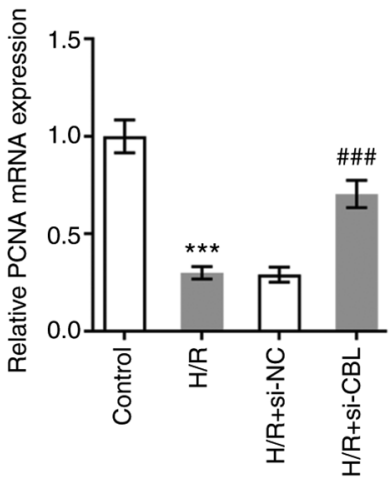

D

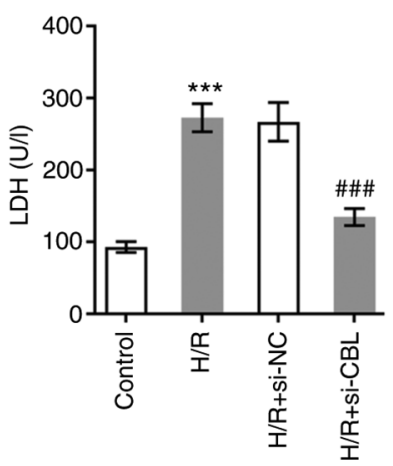

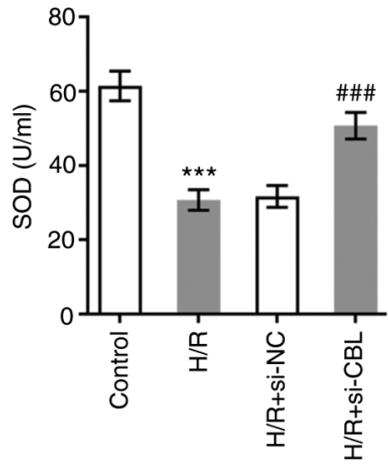
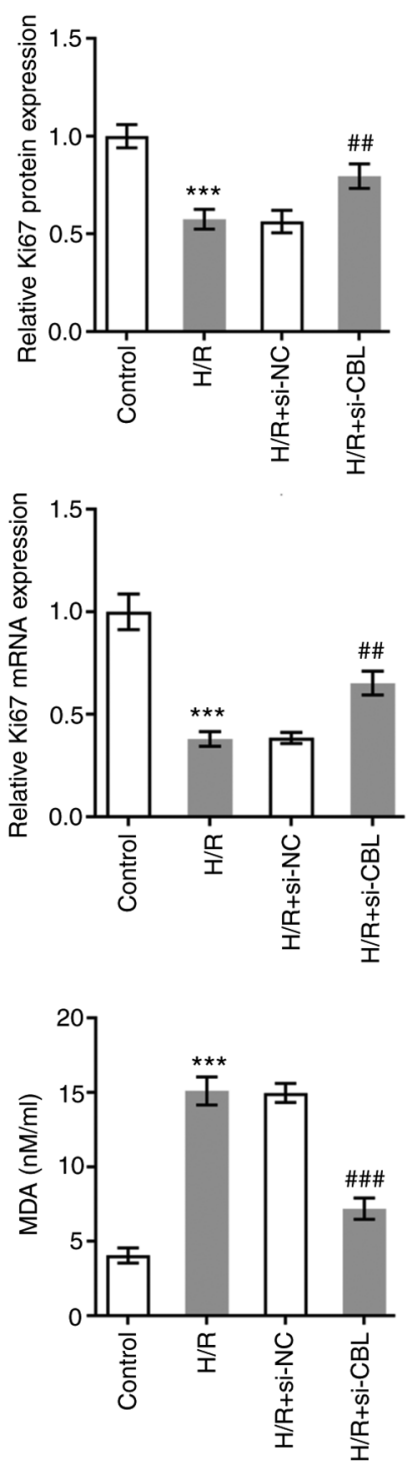

Figure 2. CBL knockdown promotes the proliferation and oxidative stress resistance of H/R-induced myocardiocytes. (A) Efficacy of transfection was detected using RT-qPCR and western blot analysis. ${ }^{* * *} \mathrm{P}<0.001$ vs. si-NC. (B) Cell viability of cells in each group was detected using Cell Counting Kit-8 assay. (C) PCNA and Ki67 protein expression in cells in each group were detected using RT-qPCR and western blot analysis. (D) Antioxidant capacity of each group of cells was assessed by measuring their $\mathrm{LDH}, \mathrm{SOD}$ and MDA levels. ${ }^{* * *} \mathrm{P}<0.001$ vs. Control; ${ }^{\# \#} \mathrm{P}<0.01$ and ${ }^{\# \# \#} \mathrm{P}<0.001 \mathrm{vs}$. H/R + si-NC. Si-, small interfering; CBL, Cbl proto-oncogene; RT-qPCR, reverse transcription-quantitative PCR; H/R, hypoxia-reoxygenation; si-NC, small interfering negative control; PCNA, proliferating cell nuclear antigen; LDH, lactate dehydrogenase; SOD, superoxide dismutase; MDA, malondialdehyde.

CBL knockdown inhibits H/R-induced myocardial apoptosis. The aforementioned treatment groups were also designated to explore the effects of CBL knockdown on cell apoptosis. The results of the TUNEL assays revealed that the number of apoptotic cells in the $\mathrm{H} / \mathrm{R}$ group was significantly increased compared with that in the control group (Fig. 3A). In the H/R + si-CBL group, the number of apoptotic cells was significantly lower compared with that in the $\mathrm{H} / \mathrm{R}+$ si-NC group (Fig. 3A). According to the results of western blot analysis, the expression levels of Bax and cleaved caspase- 3 were found to be 
A

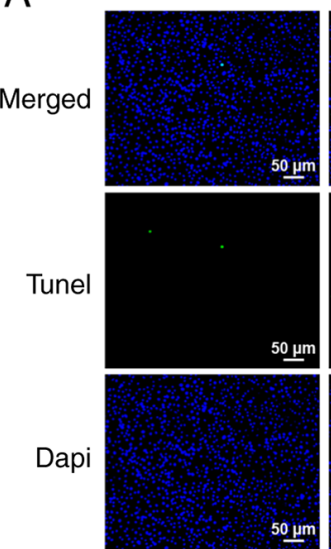

$H / R$
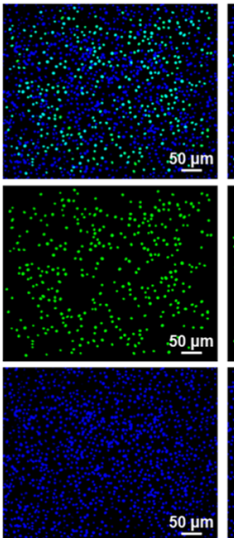

B

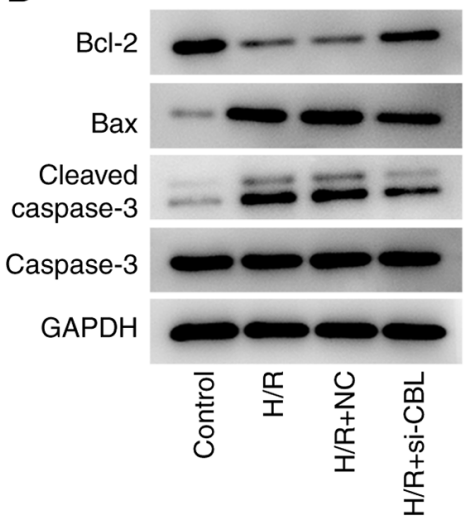

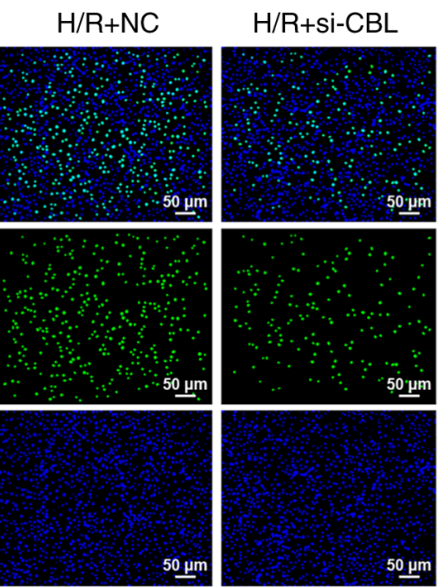
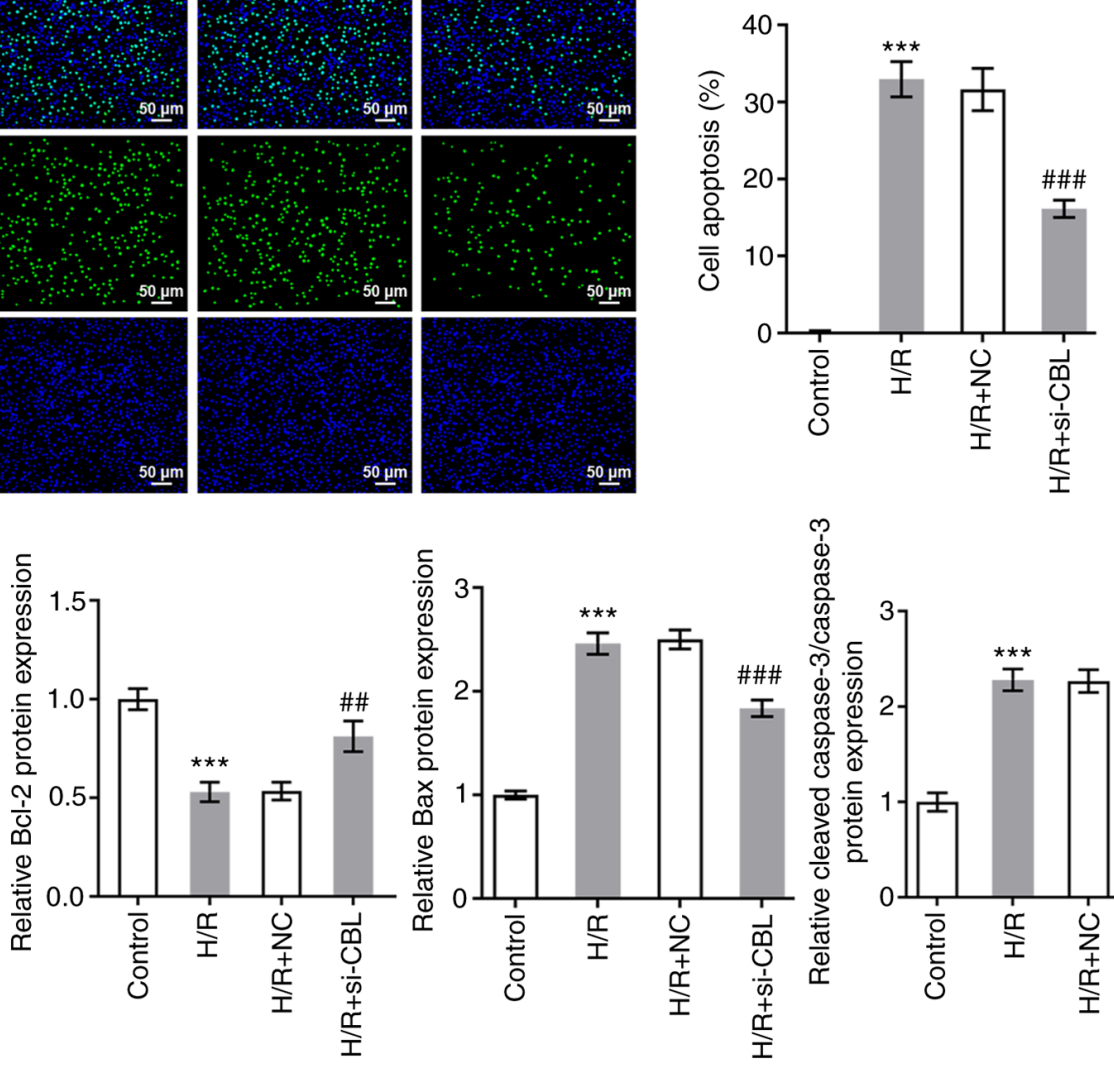

Figure 3. CBL knockdown inhibits H/R-induced myocardial apoptosis. (A) Apoptosis of cells was determined using TUNEL assay. Scale bars, $50 \mu \mathrm{m}$. (B) Expression levels of apoptosis-related proteins of cells in each group were measured using western blotting. ${ }^{* * *} \mathrm{P}<0.001$ vs. Control; ${ }^{\# \#} \mathrm{P}<0.01$ and

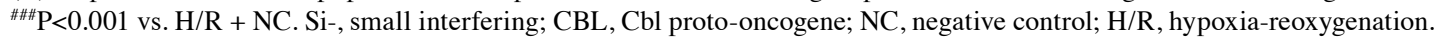

significantly upregulated in the H/R group compared with those in the control group, whilst knocking down CBL expression significantly reversed this increase in Bax and cleaved caspase-3 expression (Fig. 3B). Additionally, the trend in Bcl-2 expression was found to be opposite to that shown by Bax and cleaved caspase-3 (Fig. 3B). These results suggest that CBL knockdown can inhibit H/R-induced cell apoptosis.

CBL knockdown reduces the expression of GRB2 in $\mathrm{H} 9 \mathrm{c} 2$ rat cardiomyoblasts. Notably, GRB2 was revealed to promote the advancement of cardiac fibrosis. Moreover, according to the data on STRING database, GRB2 was predicated to be associated with CBL (Fig. 4A). The expression levels of GRB2 were therefore measured using RT-qPCR and western blot analysis. The expression levels of GRB2 in cells transfected with si-CBL were markedly lower compared with those in the si-NC group (Fig. 4B). The results of co-IP and western blot analysis revealed that both CBL and GRB2 were expressed in the input group and GRB2 protein was revealed to exist in the anti-CBL group. However, IgG could not pull down CBL and was used to rule out false positive results. This suggests that there was an association between these two proteins (Fig. 4C).

$C B L$ knockdown promotes the proliferation and oxidative stress resistance of $H / R$-induced $H 9 c 2$ rat cardiomyoblasts by downregulating GRB2 expression. To verify the mechanism by which GRB2 regulate CBL, cells were transfected with
pcDNA3.1-GRB2 before transfection efficiency was verified using RT-qPCR and western blotting (Fig. 5A). The expression of GRB2 was markedly enhanced after the cells transfection with GRB2 overexpression plasmids compared with that in the Ov-NC group. The H9c2 cells were then divided into the following five groups: Control group, $\mathrm{H} / \mathrm{R}+\mathrm{si}-\mathrm{NC}$ group, $\mathrm{H} / \mathrm{R}+\mathrm{si}-\mathrm{CBL}$ group, $\mathrm{H} / \mathrm{R}+\mathrm{si}-\mathrm{CBL}+\mathrm{Ov}-\mathrm{NC}$ group and the $\mathrm{H} / \mathrm{R}+\mathrm{si}-\mathrm{CBL}+\mathrm{Ov}-\mathrm{GRB} 2$ group. The viability of cells in each group was first examined using a CCK-8 assay. As depicted in Fig. 5B, the cell viability in H/R-induced H9c2 cells were significantly increased by CBL-silencing in comparison with that in $\mathrm{H} / \mathrm{R}+$ si-NC group. Notably, GRB2 overexpression slightly decreased the cell viability in comparison with that in $\mathrm{H} / \mathrm{R}+\mathrm{si}-\mathrm{CBL}+\mathrm{Ov}-\mathrm{NC}$, revealing that GRB2 overexpression didn't have significant influence on viability of H/R-induced H9c2 cells transfection with siRNA specific CBL. In addition, the expression levels of PCNA and Ki67 were both significantly downregulated in the $\mathrm{H} / \mathrm{R}+\mathrm{si}-\mathrm{CBL}+\mathrm{Ov}-\mathrm{GRB} 2$ group compared with those in the $\mathrm{H} / \mathrm{R}+\mathrm{si}-\mathrm{CBL}+\mathrm{Ov}-\mathrm{NC}$ group (Fig. 5C). LDH, SOD and MDA levels were also assessed. SOD levels were found to be significantly downregulated, whilst LDH and MDA levels were significantly upregulated following GRB2 overexpression, compared with those in the $\mathrm{H} / \mathrm{R}+\mathrm{si}-\mathrm{CBL}+\mathrm{Ov}-\mathrm{NC}$ group (Fig. 5D).

CBL knockdown inhibits $H / R$-induced myocardial apoptosis by downregulating GRB2 expression. The same five groups 
A

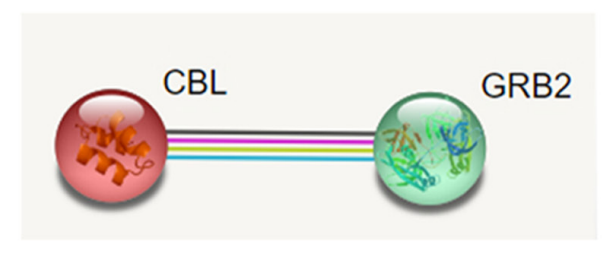

B

C

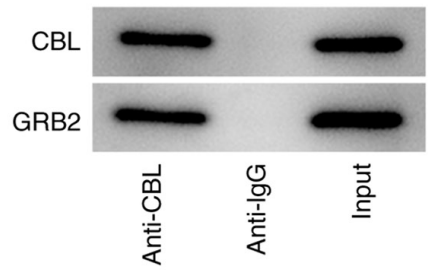

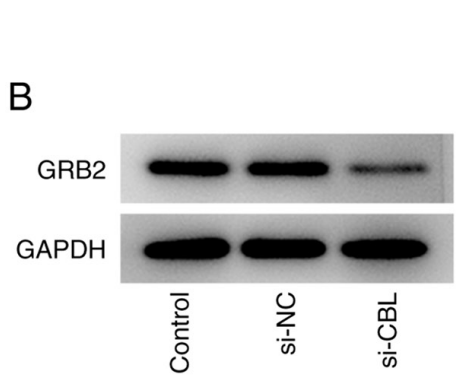
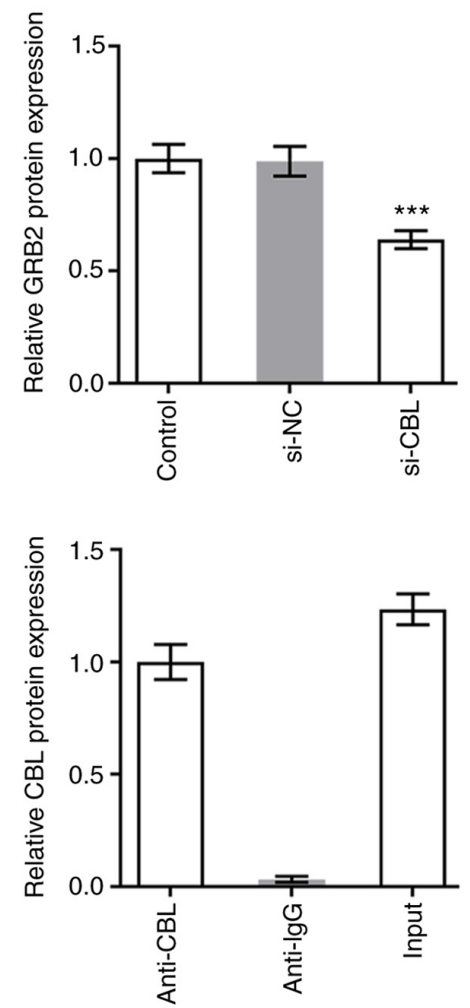
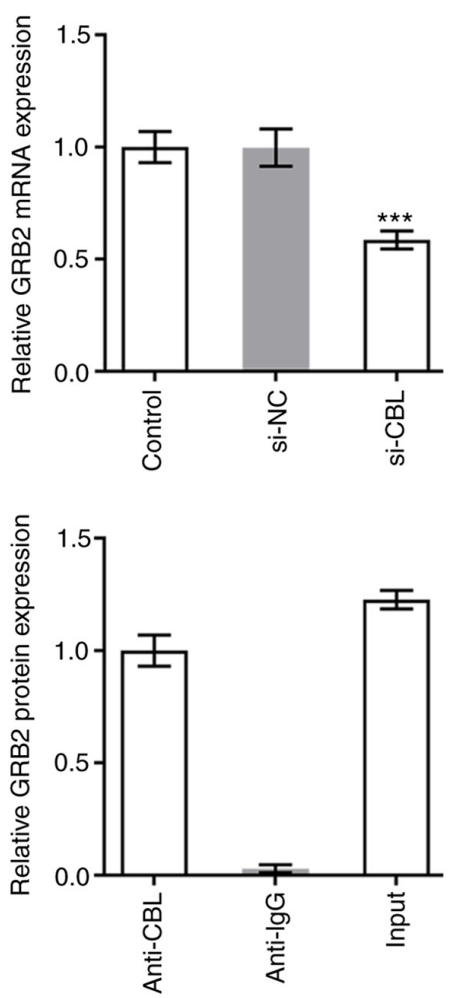

Figure 4. CBL knockdown inhibits the expression of GRB2 in H9c2 rat cardiomyoblasts. (A) Association between CBL and GRB2 was predicted using Search Tool for the Retrieval of Interacting Genes/Proteins. (B) Expression levels of GRB2 in the H9c2 rat cardiomyoblasts were measured using reverse transcription-quantitative PCR and western blot analysis. (C) Association between CBL and GRB2 was verified using co-IP followed by western blot analysis. ${ }^{* * *} \mathrm{P}<0.001$ vs. NC. $\mathrm{CBL}, \mathrm{Cbl}$ proto-oncogene; NC, negative control; Si-, small interfering; GRB2, Growth factor receptor-bound protein 2; co-IP, co-immunoprecipitation.

of $\mathrm{H} 9 \mathrm{c} 2$ cells aforementioned were used to explore the effects of GRB2 and CBL on apoptosis. The levels of apoptosis and the expression levels of apoptosis-related proteins in each group were determined using a TUNEL assay and western blot analysis, respectively. The number of apoptotic cells in the H/R + si-CBL + Ov-GRB2 group was significantly greater compared with that in the $\mathrm{H} / \mathrm{R}+\mathrm{si}-\mathrm{CBL}+\mathrm{Ov}-\mathrm{NC}$ group (Fig. 6A). In addition, compared with $\mathrm{H} / \mathrm{R}+\mathrm{si}-\mathrm{NC}$, CBL-silencing significantly upregulated Bcl-2 expression but significantly downregulated the expression levels of Bax and cleaved caspase-3; while GRB2 overexpression reversed the inhibitory effects of CBL-silencing on apoptosis, evidenced by the downregulated Bcl-2 expression but upregulated expression levels of Bax and cleaved caspase- 3 in contrast to that in the H/R + si-CBL + Ov-NC group (Fig. 6B).

\section{Discussion}

In previous experimental and clinical studies, a number of treatment strategies for preventing MIRI have been proposed, including ischemic pre-conditioning (IPC), ischemic post-conditioning (IPost), remote ischemic conditioning (RIC) and drug intervention (30). IPC entails multiple transient ischemia-reperfusion treatments in coronary arteries to activate the endogenous protective mechanisms and enhance ischemic tolerance (31). IPost consists of allowing the coronary blood to flow back for a period of time before obstructing it again (32). This reperfusion/obstruction process is repeated several times to complete the reperfusion treatment (32). RIC entails the prevention of MIRI by simultaneously applying $\geq$ one brief intermittent reperfusion cycles to another organ or tissue (33). In addition, various novel drug targets have been discovered, where examples such as Exenatide and Cyclosporin have demonstrated potential (30). However, to date no effective therapeutic agent exist for the prevention and treatment of reperfusion injury (34). A previous study found that pre-administration of fish oil and flaxseed oil to rats alleviated MIRI through regulation of the mitochondrial membrane permeability transport pore (35). In addition, a number of genes have been considered to be promising targets, such as sirtuin 3 (36), melatonin receptor 2 (37) and protein inhibitor of activated STAT1 (16). Due to the lack of known therapeutic targets approved for clinical use, the present study assessed the effects of CBL on the proliferation, antioxidant capacity and apoptosis of $\mathrm{H} 9 \mathrm{c} 2$ rat cardiomyoblasts induced by $\mathrm{H} / \mathrm{R}$. The results suggested that $\mathrm{CBL}$ may serve to be an effective therapeutic target in the future. 


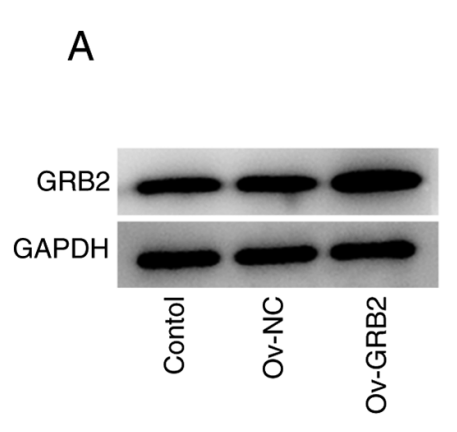

C

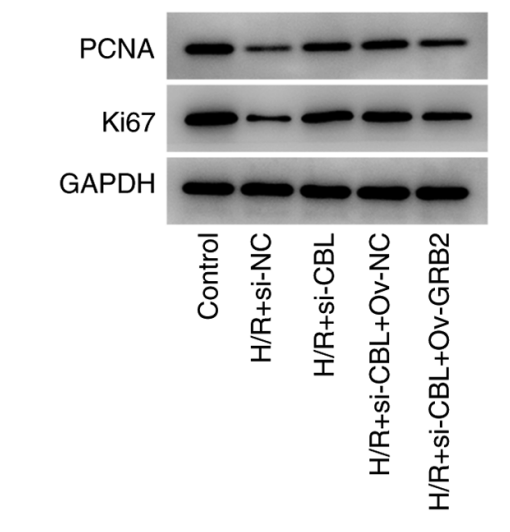

D

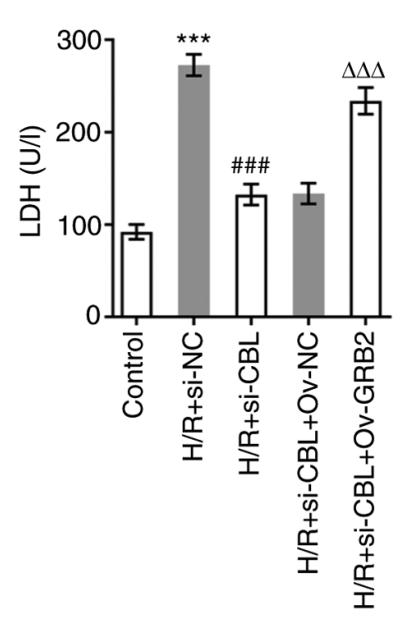

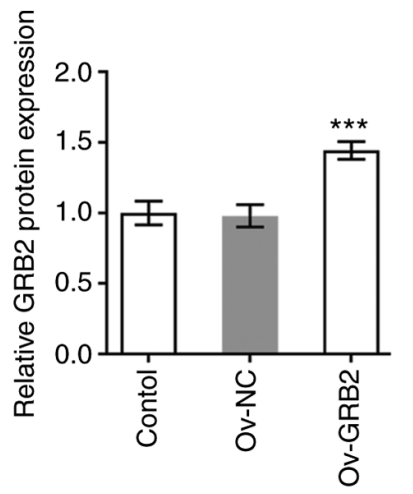

음

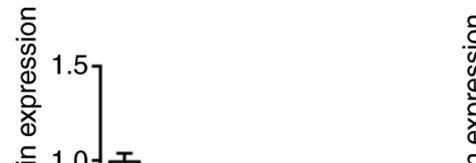

B

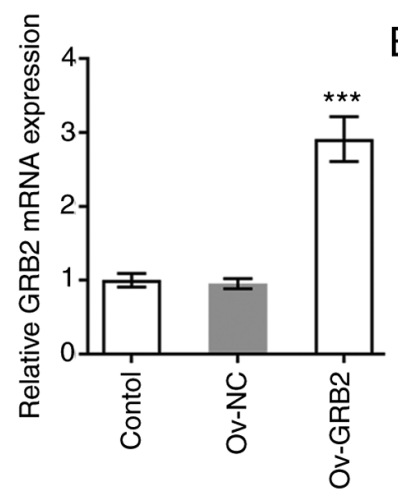

.흐.

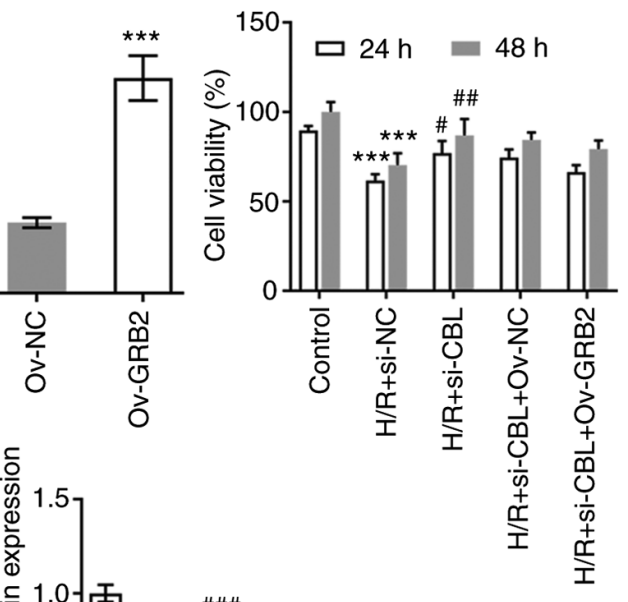

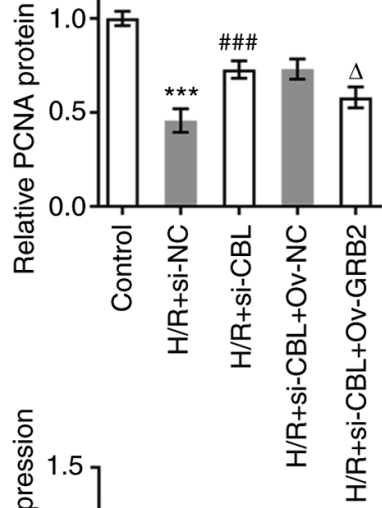
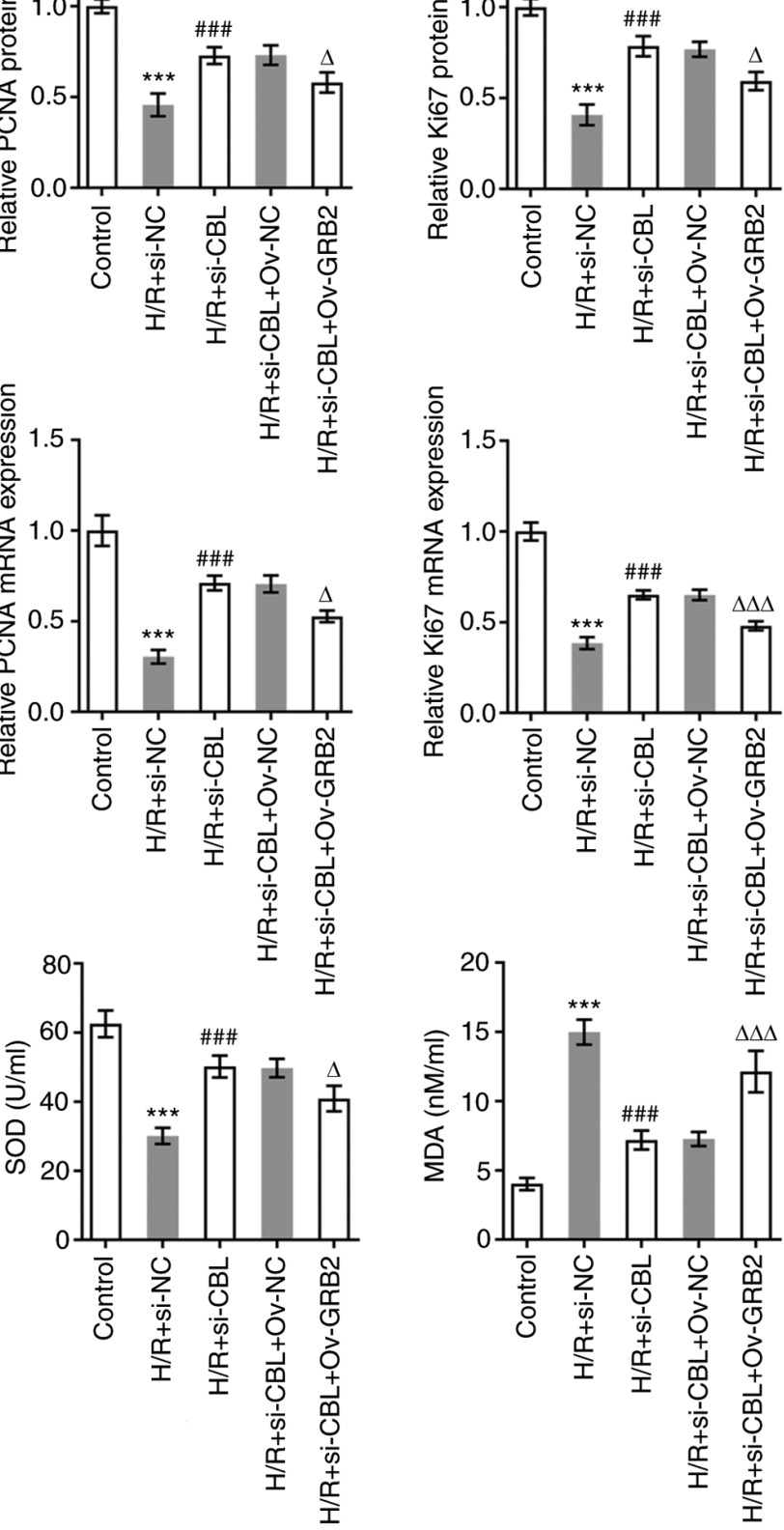

Figure 5. CBL knockdown promotes the proliferation and oxidation resistance of H/R-induced H9c2 rat cardiomyoblasts by downregulating of GRB2 expression. (A) Transfection efficiency of Ov-GRB2 was verified using RT-qPCR and western blot analysis. ${ }^{* * *} \mathrm{P}<0.001$ vs. Ov-NC. (B) Cell viability in each group was examined using Cell Counting Kit-8 assay. (C) Expression levels of PCNA and Ki67 were measured using western blot analysis. (D) Antioxidant capacity

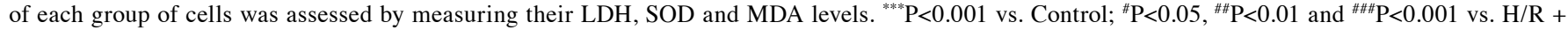
si-NC; ${ }^{\Delta} \mathrm{P}<0.05$ and ${ }^{\Delta \Delta \Delta} \mathrm{P}<0.001$ vs. H/R + si-CBL + Ov-NC. Si-, small interfering; CBL, Cbl proto-oncogene; NC, negative control; Ov, overexpression; H/R, hypoxia-reoxygenation; GRB2, Growth factor receptor-bound protein 2; RT-qPCR, reverse transcription-quantitative PCR; PCNA, proliferating cell nuclear antigen; LDH, lactate dehydrogenase; SOD, superoxide dismutase; MDA, malondialdehyde. 
A
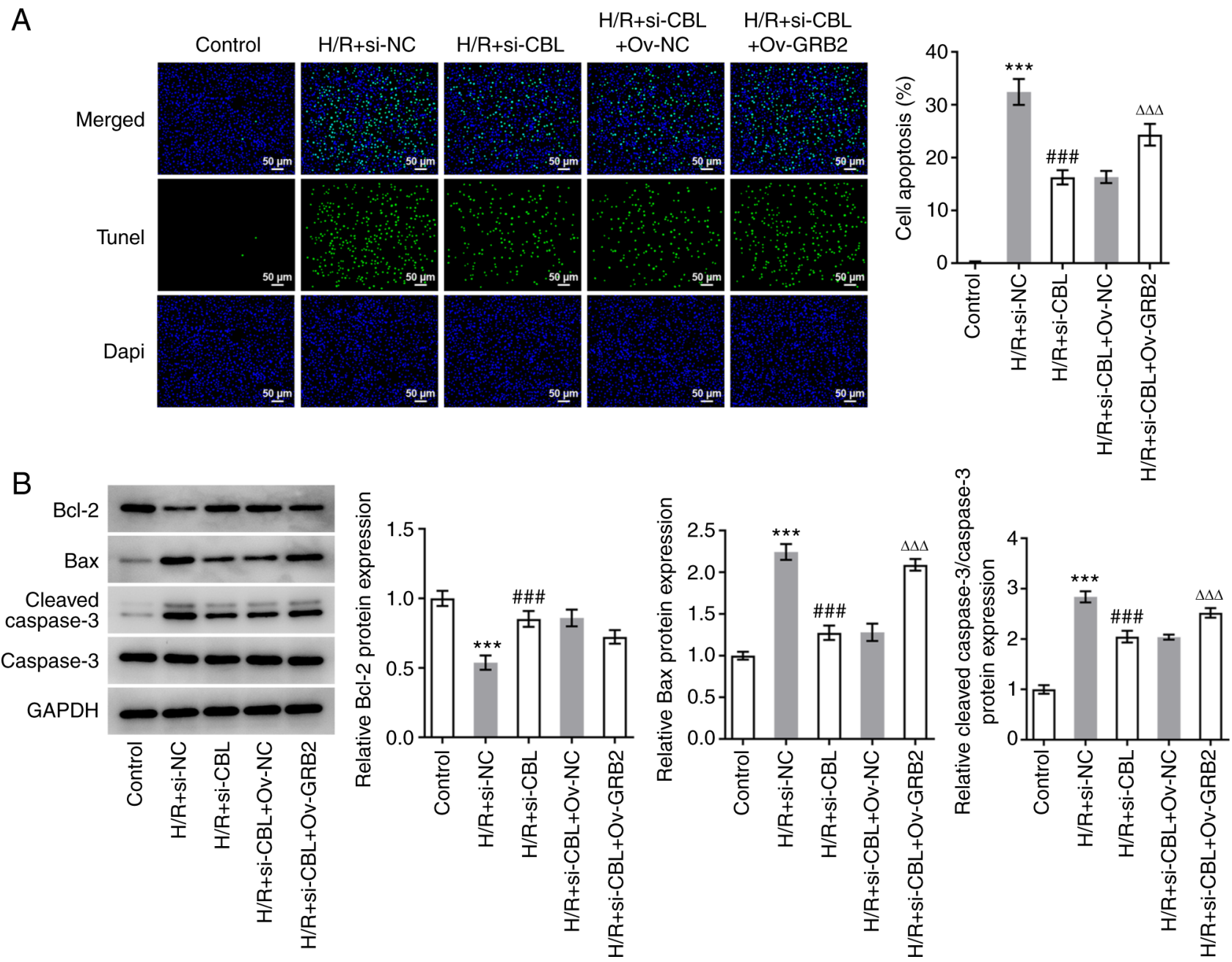

Figure 6. CBL knockdown inhibits H/R-induced myocardial apoptosis by downregulating GRB2 expression. (A) Apoptosis of cells was determined using a TUNEL assay. Scale bars, $50 \mu \mathrm{m}$. (B) Expression levels of apoptosis-related proteins in each group were measured using western blot analysis. ${ }^{* * * *} \mathrm{P}<0.001$ vs. Control; ${ }^{\# \#} \mathrm{P}<0.001$ vs. H/R + si-NC; ${ }^{\Delta \Delta} \mathrm{P}<0.001$ vs. H/R + si-CBL + Ov-NC. Si-, small interfering; CBL, Cbl proto-oncogene; NC, negative control; $\mathrm{Ov}$, overexpression; H/R, hypoxia-reoxygenation; GRB2, Growth factor receptor-bound protein 2.

Under normal physiological conditions, OFR increases lipid peroxidation, resulting in the production of MDA and LDH $(38,39)$. OFR can be scavenged by SOD and glutathione, which maintains the balance between the generation and elimination of OFR (40). The oxidative capacity of cardiomyocytes is significantly enhanced during MIRI, where unsaturated fatty acids on the membrane can be attacked to trigger alterations in the cell membrane functional unit structure and function (19). The increased production of OFRs may cause cardiomyocyte necrosis and dysfunction (41). Therefore, the present study explored the effects of CBL on the antioxidant capacity of cardiomyocytes following $\mathrm{H} / \mathrm{R}$, which found that CBL knockdown improved the antioxidant capacity of this $\mathrm{H} 9 \mathrm{c} 2$ cell model. In addition, associated proteins were predicted using the STRING database, where it was found that GRB2 and CBL may be associated. Additionally, GRB2-silencing was reported to suppress TGF- $\beta 1$-induced collagen production and cell viability in cardiac fibrosis, revealing that GRB2 participated in the promotion of cardiac fibrosis (42). Therefore, it is proposed that GRB2 may be involved in the role of CBL in cardiomyocytes. Results in the present study revealed that GRB2 was involved in the mechanism of action of CBL.
Apoptosis is the most common type of programmed cell death and has been shown to be the major pathological mechanism underlying MIRI (15). Aberrant levels of apoptosis will aggravate the destruction of the myocardium, resulting in a decrease in the number of viable myocardial cells and thus cardiac function, thereby aggravating myocardial damage (43). Mitochondria are vital for the production of ATP and the induction of cell apoptosis (44). Cytochrome $c$, a marker of activation of the mitochondrial apoptosis pathway, can activate pro-caspase 9, thereby promoting the activation of caspase-3 (45). In addition, Bax is a pro-apoptotic protein (46). Following activation of Bax, it enters the mitochondria from the cytoplasm, increases the permeability of the mitochondrial membrane and promotes the release of cytochrome $c$, thereby mediating cell apoptosis (47). $\mathrm{Bcl}-2$ is an anti-apoptotic protein, which can inhibit the release of cytochrome $c$ from the mitochondria and inhibit cell apoptosis (48). In the present study, CBL knockdown downregulated the expression of Bax and caspase-3 whilst upregulating the expression of $\mathrm{Bcl}-2$, suggesting that it can alleviate the apoptosis of cardiomyocytes induced by $\mathrm{H} / \mathrm{R}$.

In conclusion, the results of the present study revealed that CBL expression was upregulated in the plasma of patients 
with ICM. CBL knockdown promoted the proliferation and increased the antioxidant capacity of damaged cardiomyocytes induced by $\mathrm{H} / \mathrm{R}$ whilst inhibiting cell apoptosis, by regulating the expression of GRB2. CBL may thus serve as a target for the management of MIRI. Whilst the underlying mechanism was elucidated to a certain depth, the present article is limited in that only in vitro experiments were performed. Future studies should verify these findings using in vivo models.

\section{Acknowledgements}

Not applicable.

\section{Funding}

No funding was received.

\section{Availability of data and materials}

The datasets used and/or analyzed during the current study are available from the corresponding author on reasonable request.

\section{Authors' contributions}

ZL and XL designed the study. ZL, XL, BH and QY performed the experiments. JL revised the manuscript for important intellectual content. JL and YH collected the clinical data and analyzed the data. All authors have read and approved the final manuscript. JL and YH can confirm the authenticity of the raw data.

\section{Ethics approval and consent to participate}

All procedures were performed in accordance with the Declaration of the Institutional Research Committee's Ethical standards, as well as the 1964 Declaration of Helsinki and its later amendments. The Ethics Committee of the Second People's Hospital of Chengdu approved the involvement of human participants, and the study ran from August 2017 to August 2019 (approval no. 2017081302). All the patients or their parents/guardians provided informed consent.

\section{Patient consent for publication}

Not applicable.

\section{Competing interests}

The authors declare that they have no competing interests.

\section{References}

1. Brueck M, Koerholz D, Nuernberger W, Juergens H, Goebel U and Wahn V: Elimination of 1-asparaginase in children treated for acute lymphoblastic leukemia. Dev Pharmacol Ther 12: 200-204, 1989.

2. Roth GA, Mensah GA, Johnson CO, Addolorato G, Ammirati E, Baddour LM, Barengo NC, Beaton AZ, Benjamin EJ, Benziger CP, et al: Global burden of cardiovascular diseases and risk factors, 1990-2019: Update from the GBD 2019 study. J Am Coll Cardiol 76: 2982-3021, 2020.
3. Dang H, Ye Y, Zhao X and Zeng Y: Identification of candidate genes in ischemic cardiomyopathy by gene expression omnibus database. BMC Cardiovasc Disord 20: 320, 2020.

4. Dixon SR, Henriques JP, Mauri L, Sjauw K, Civitello A, Kar B, Loyalka P, Resnic FS, Teirstein P, Makkar R, et al: A prospective feasibility trial investigating the use of the Impella 2.5 system in patients undergoing high-risk percutaneous coronary intervention (The PROTECT I Trial): Initial U.S. experience. JACC Cardiovasc Interv 2: 91-96, 2009.

5. Henriques JP, Remmelink M, Baan J Jr, van der Schaaf RJ, Vis MM, Koch KT, Scholten EW, de Mol BA, Tijssen JG, Piek JJ and de Winter RJ: Safety and feasibility of elective high-risk percutaneous coronary intervention procedures with left ventricular support of the Impella recover LP 2.5. Am J Cardiol 97: 990-992, 2006.

6. Kiyooka T and Satoh Y: Mid-ventricular obstructive hypertrophic cardiomyopathy with an apical aneurysm caused by vasospastic angina. Tokai J Exp Clin Med 39: 29-33, 2014.

7. Fanari Z, Abraham N, Hammami S and Qureshi WA: High-risk acute coronary syndrome in a patient with coronary subclavian steal syndrome secondary to critical subclavian artery stenosis. Case Rep Cardiol 2014: 175235, 2014.

8. Wang $X$, Chen J and Huang X: Rosuvastatin attenuates myocardial ischemia-reperfusion injury via upregulating miR-17-3p-mediated autophagy. Cell Reprogram 21: 323-330, 2019.

9. Bulluck $\mathrm{H}$ and Hausenloy DJ: Ischaemic conditioning: Are we there yet? Heart 101: 1067-1077, 2015.

10. Hausenloy DJ and Yellon DM: Myocardial ischemia-reperfusion injury: A neglected therapeutic target. J Clin Invest 123: 92-100, 2013.

11. Wu MY, Yiang GT, Liao WT, Tsai AP, Cheng YL, Cheng PW, Li CY and Li CJ: Current mechanistic concepts in ischemia and reperfusion injury. Cell Physiol Biochem 46: 1650-1667, 2018.

12. Ziegler $M$, Wang $X$ and Peter K: Platelets in cardiac ischaemia/reperfusion injury: A promising therapeutic target. Cardiovasc Res 115: 1178-1188, 2019.

13. Fanari Z, Weiss S and Weintraub WS: Cost effectiveness of antiplatelet and antithrombotic therapy in the setting of acute coronary syndrome: Current perspective and literature review. Am J Cardiovasc Drugs 15: 415-427, 2015.

14. World Health Organization. The top 10 causes of death. Available from: http://www.who.int/mediacentre/factsheets/fs310/en/. WHO website, 2018.

15. Huang ZQ, Xu W, Wu JL, Lu X and Chen XM: MicroRNA-374a protects against myocardial ischemia-reperfusion injury in mice by targeting the MAPK6 pathway. Life Sci 232: 116619, 2019.

16. Xie B, Liu X, Yang J, Cheng J, Gu J and Xue S: PIAS1 protects against myocardial ischemia-reperfusion injury by stimulating PPAR $\gamma$ SUMOylation. BMC Cell Biol 19: 24, 2018.

17. Liang S, Ping $Z$ and Ge J: Coenzyme Q10 regulates antioxidative stress and autophagy in acute myocardial ischemia-reperfusion injury. Oxid Med Cell Longev 2017: 9863181, 2017.

18. Chen S, Zhu Q, Ju H, Hao J, Lai Z, Zou C, Zhang W, Zhao S, Chen X, Zhang H, et al: The role of oxygen free radicals in myocardial ischemia/reperfusion injury. Chin Med Sci J 6: 127-131, 1991.

19. Tian L, Cao W, Yue R, Yuan Y, Guo X, Qin D, Xing J and Wang X: Pretreatment with Tilianin improves mitochondrial energy metabolism and oxidative stress in rats with myocardial ischemia/reperfusion injury via AMPK/SIRT1/PGC-1 alpha signaling pathway. J Pharmacol Sci 139: 352-360, 2019.

20. Grøvdal LM, Stang E, Sorkin A and Madshus IH: Direct interaction of Cbl with pTyr 1045 of the EGF receptor (EGFR) is required to sort the EGFR to lysosomes for degradation. Exp Cell Res 300: 388-395, 2004.

21. Schmidt $\mathrm{MHH}$ and Dikic I: The $\mathrm{Cbl}$ interactome and its functions. Nat Rev Mol Cell Biol 6: 907-918, 2005.

22. Wu WJ, Tu S and Cerione RA: Activated Cdc 42 sequesters c-Cbl and prevents EGF receptor degradation. Cell 114: 715-725, 2003.

23. Swaminathan $\mathrm{G}$ and Tsygankov AY: The $\mathrm{Cbl}$ family proteins: Ring leaders in regulation of cell signaling. J Cell Physiol 209: 21-43, 2006.

24. Rafiq K, Kolpakov MA, Seqqat R, Guo J, Guo X, Qi Z, Yu D, Mohapatra B, Zutshi N, An W, et al: c-Cbl inhibition improves cardiac function and survival in response to myocardial ischemia. Circulation 129: 2031-2043, 2014.

25. Yu SY, Dong B, Fang ZF, Hu XQ, Tang L and Zhou SH: Knockdown of lncRNA AK139328 alleviates myocardial ischaemia/reperfusion injury in diabetic mice via modulating miR-204-3p and inhibiting autophagy. J Cell Mol Med 22: 4886-4898, 2018. 
26. Richardson P, McKenna W, Bristow M, Maisch B, Mautner B, O'Connell J, Olsen E, Thiene G, Goodwin J, Gyarfas I, et al: Report of the 1995 World Health Organization/international society and federation of cardiology task force on the definition and classification of cardiomyopathies. Circulation 93: 841-842, 1996.

27. Liu D: Effects of Nicorandil combined with Danhong injection on SOD and MDA content in patients with myocardial ischemia-reperfusion injury. Mod J Integr Tradit Chin West Med 1: 78-80, 2016.

28. Livak KJ and Schmittgen TD: Analysis of relative gene expression data using real-time quantitative PCR and the 2(-Delta Delta C(T)) method. Methods 25: 402-408, 2001

29. Szklarczyk D, Gable AL, Nastou KC, Lyon D, Kirsch R, Pyysalo S, Doncheva NT, Legeay M, Fang T, Bork P, et al: The STRING database in 2021: Customizable protein-protein networks, and functional characterization of user-uploaded gene/measurement sets. Nucleic Acids Res 49: D605-D612, 2021.

30. Hausenloy DJ: Conditioning the heart to prevent myocardial reperfusion injury during PPCI. Eur Heart J Acute Cardiovasc Care 1: 13-32, 2012.

31. Hausenloy DJ, Candilio L, Evans R, Ariti C, Jenkins DP, Kolvekar S, Knight R, Kunst G, Laing C, Nicholas J, et al: Remote ischemic preconditioning and outcomes of cardiac surgery. N Engl J Med 373: 1408-1417, 2015.

32. Miao W, Yan Y, Bao TH, Jia WJ, Yang F, Wang Y, Zhu YH, Yin $\mathrm{M}$ and Han JH: Ischemic postconditioning exerts neuroprotective effect through negatively regulating PI3K/Akt2 signaling pathway by microRNA-124. Biomed Pharmacother 126: 109786 , 2020 .

33. Heusch G, Bøtker HE, Przyklenk K, Redington A and Yellon D: Remote ischemic conditioning. J Am Coll Cardiol 65: 177-195, 2015.

34. Soares ROS,Losada DM,Jordani MC,ÉvoraP and Castro-E-Silva O: Ischemia/reperfusion injury revisited: An overview of the latest pharmacological strategies. Int J Mol Sci 20: 5034, 2019.

35. Ivary SHA, Jajarmy N, Shahri MK, Shokoohi M, Shoorei H, Ebadi A, Moghimian M and Sigaroodi F: Effect of fish and flaxseed oil supplementation on isoprenaline-induced myocardial infarction in rats: Inhibition of mitochondrial permeability transition pore opening. Crescent J Med Biol Sci 6: 158-163, 2019.

36. Zheng Y, Shi B, Ma M, Wu X and Lin X: The novel relationship between Sirt3 and autophagy in myocardial ischemia-reperfusion. J Cell Physiol 234: 5488-5495, 2019.

37. Han D, Wang Y, Chen J, Zhang J, Yu P, Zhang R, Li S, Tao B, Wang Y, Qiu Y, et al: Activation of melatonin receptor 2 but not melatonin receptor 1 mediates melatonin-conferred cardioprotection against myocardial ischemia/reperfusion injury. J Pineal Res 67: e12571, 2019.

38. Li J, Zheng X, Ma X, Xu X, Du Y, Lv Q, Li X, Wu Y, Sun H, Yu L and Zhang Z: Melatonin protects against chromium(VI)-induced cardiac injury via activating the AMPK/Nrf2 pathway. J Inorg Biochem 197: 110698, 2019.
39. Yang D, Yang Q, Fu N, Li S, Han B, Liu Y, Tang Y, Guo X, Lv Z and Zhang Z: Hexavalent chromium induced heart dysfunction via Sesn2-mediated impairment of mitochondrial function and energy supply. Chemosphere 264: 128547, 2021.

40. Bouayed J and Bohn T: Exogenous antioxidants-double-edged swords in cellular redox state: Health beneficial effects at physiologic doses versus deleterious effects at high doses. Oxid Med Cell Longev 3: 228-237, 2010.

41. Puente BN, Kimura W, Muralidhar SA, Moon J, Amatruda JF, Phelps KL, Grinsfelder D, Rothermel BA, Chen R, Garcia JA, et al: The oxygen-rich postnatal environment induces cardiomyocyte cell-cycle arrest through DNA damage response. Cell 157: 565-579, 2014

42. Sun F, Zhuang Y, Zhu H, Wu H, Li D, Zhan L, Yang W, Yuan Y, Xie Y, Yang S, et al: LncRNA PCFL promotes cardiac fibrosis via miR-378/GRB2 pathway following myocardial infarction. J Mol Cell Cardiol 133: 188-198, 2019.

43. Peng X, Lin L, Zhou X, Yang D, Cao Y, Yin T and Liu Y: miR-133b inhibits myocardial ischemia-reperfusion-induced cardiomyocyte apoptosis and accumulation of reactive oxygen species in rats by targeting YES1. Nan Fang Yi Ke Da Xue Xue Bao 40: 1390-1398, 2020 (In Chinese).

44. Su C, Fan X, Xu F, Wang J and Chen Y: Prostaglandin E1 attenuates post-cardiac arrest myocardial dysfunction through inhibition of mitochondria-mediated cardiomyocyte apoptosis. Mol Med Rep 23: 110, 2021.

45. Chuang GC, Xia H, Mahne SE and Varner KJ: Environmentally persistent free radicals cause apoptosis in $\mathrm{HL}-1$ cardiomyocytes. Cardiovasc Toxicol 17: 140-149, 2017.

46. Pirocanac EC, Nassirpour R, Yang M, Wang J, Nardin SR, Gu J, Fang B, Moossa AR, Hoffman RM and Bouvet M: Bax-induction gene therapy of pancreatic cancer. J Surg Res 106: 346-351, 2002.

47. Dejean LM, Martinez-Caballero S, Guo L, Hughes C, Teijido O, Ducret T, Ichas F, Korsmeyer SJ, Antonsson B, Jonas EA and Kinnally KW: Oligomeric Bax is a component of the putative cytochrome $\mathrm{c}$ release channel MAC, mitochondrial apoptosis-induced channel. Mol Biol Cell 16: 2424-2432, 2005.

48. Yang J, Liu X, Bhalla K, Kim CN, Ibrado AM, Cai J, Peng TI, Jones DP and Wang X: Prevention of apoptosis by Bcl-2: Release of cytochrome c from mitochondria blocked. Science 275: 1129-1132, 1997.

This work is licensed under a Creative Commons Attribution-NonCommercial-NoDerivatives 4.0 International (CC BY-NC-ND 4.0) License. 